\title{
Estimation of waste mobile phones in the Philippines using neural networks
}

\author{
Galang M.G.K.* and Ballesteros Jr. F.* \\ ${ }^{1}$ Department of Environmental Engineering, University of the Philippines, Diliman, Quezon City 1101, Metro Manila, Philippines \\ Received: 24/11/2017, Accepted: 22/03/2018, Available online: 26/09/2018 \\ *to whom all correspondence should be addressed: e-mail: markginogalang@gmail.com, fcballesteros@up.edu.ph \\ https://doi.org/10.30955/gnj.002534
}

\begin{abstract}
Waste mobile phone is one of the subgroups of e-waste which is defined as discarded electronic products in the Philippine context. This study estimated current and projected quantities of waste mobile phones in the country using feed forward neural network. The neural network architecture used had three layers: (i) input layer, (ii) hidden layer, and (iii) output layer. Seven input factors were fed to the network: (i) population, (ii) literacy rate, (iii) mobile connections, (iv) mobile subscribers, (v) gross domestic product (GDP), (vi) GDP per capita, and (vii) US dollar to Philippine peso exchange rate. These input factors were selected based on the criteria provided in the study by the Groupe Spéciale Mobile Association (GSMA) Intelligence in 2015 on why the Philippines is an innovation hub in mobile industry and the availability of data from the sources. The structure was designed with five hidden layers which consisted of (i) six neurons for layer 1, (ii) five neurons for layer 2, (iii) four neurons for layer 3, (iv) three neurons for layer 4 , and (v) two neurons for layer 5 . The neural network was designed to initially calculate the sales of mobile phones before estimating waste mobile phone generation. Visual Gene Developer 1.7 Software was used which achieved a sum of squared error of 0.00001 . Estimated values were found to be in good agreement with a calculated accuracy of $99 \%$. This study can be used by policy makers as basis for strategy formulation and as guideline and baseline data for establishing a proper management system. Neural network performed better than the traditional linear extrapolation method for forecasting of data.
\end{abstract}

Keywords: Feed-forward neural network, eWaste, mobile phones.

\section{Introduction}

Mobile phones have been one of the most desirable devices in the Philippines as it is the preferred mode of communication by $65 \%$ of Filipinos (GSMA Intelligence, 2015; The Statistics Portal, 2015). Mobile devices are classified into two categories: smartphones and feature phones. Smartphones are mobile devices that perform many functions of an integrated computer while feature phones are basically low-end mobile phones. Smartphones outperform feature phones because of their advanced operating systems, thus having higher penetration rates (GSMA Intelligence, 2014). This study used a combination of the volume of waste mobile phones from both categories in the country. According to Sata (2013), the two factors that affect the consumers' behaviors in buying mobile phones are the price and the features of the device. This is affirmed by the Euromonitor International (2015) and GSMA Intelligence (2015). Araújo et al. (2012) classified mobile phones under non-mature markets which mean that their demand grows faster than the population. In this case, bulk quantity of waste mobile phone is expected to increase due to the bustling transition of mobile phones in the market.

Managing this particular type of e-waste is a pressing environmental challenge which may require that government authorities revise and update current policies and formulate appropriate guidelines (EMB, 1990). In the Philippines, an estimation of e-waste that is recycled, re-used, stored, and disposed in the landfill was conducted by Peralta and Fontanos (2006) but mobile phones were excluded from the study. Although there are various estimation models available in the literature that use input-output analysis (Steubing et al., 2010; Wang et al., 2013; Li et al., 2014), time series (Dwivedy et al., 2010), forecasting and regression models (Petridis et al., 2015; Habuer et al., 2015), End-of-Life or Delay Model (Polak et al., 2012) and market analysis models (Araujo et al., 2011), there is limited use of data mining techniques such as artificial intelligence of which neural networks is an example.

The neural networks method is a powerful tool for predicting values because of its non-parametric property (Sohl et al., 1995). It is inspired by the human brain that consists of neurons; each is connected to other neurons known as synapses which are activated depending on the input pulse. Synapses link information between connected neurons which are arranged in a layered fashion (Theodoridis, 2015). This study aim to determine the factors that influence mobile phones purchasing and to develop a neural network model to estimate sales of 
mobile phones and eventually the waste mobile phones in the Philippines.

\section{Methodology}

\subsection{Materials}

\subsubsection{Input factors}

In the absence of waste mobile phone data over the past years, the neural network model was initially used to compute for the sales of mobile phones before estimating the waste mobile phones in the country. To obtain the ideal input parameters, information from the GSMA Intelligence (2015) were used as guidelines as to why the Philippines is a major innovation hub in the mobile ecosystem. According to GSMA Intelligence (2015), the country is continuously successful in innovation due to (i) demography, (ii) economic credibility, and (iii) mobile operators active in innovation. In line with this, the study employed factors that are related to the cited criteria. For demography, population and literacy rate were used as input factors. For economic credibility, the inputs used were gross domestic product (GDP), average income of every Filipino (GDP per capita), and US dollar to Philippine peso exchange rate. For mobile operators, data for the number of mobile connections and unique mobile subscribers were used. The same report explained that number of mobile connections are the number of sim (Subscriber Identity Module) cards that an individual possesses while unique subscribers are those individuals subscribed to a mobile service and that person can hold multiple mobile connections. Historical sales data from 2010 to 2015 obtained from Euromonitor International were used as reference data for the prediction output. Data on imported mobile phones may sustain the material flow of new units in the country which can improve the prediction accuracy of the model, however, imported mobile phones were not included in this study since data from the government's trade and statistics office were not available. To address this gap, other input variables were considered (i.e. unique mobile subscribers and sales of mobile phones) that are related to the factors affect the circulation of mobile units in the country.

Seven input factors were used to generate a single output value which is the sales of mobile phones.This study will consider the lifespan of mobile phones with an average of 3 years (The Statistics Portal, 2015) however, there are numerous methods available to estimate the lifespan of waste electronics and electrical equipment (i.e. Weibull distribution model, Input-output model etc.).

A survey with 150 respondents was conducted to evaluate the disposal/replacement behaviors of consumers. The survey consisted of questions about the period the consumers used their mobile phones before the phones were disposed/replaced. The results indicated that consumers dispose/replace their mobile phones within less than one year ( $<1$ year) of usage, between 1 year to 2 years, and 2 years and above. The results of the estimation shall be the values for the volume of waste mobile phones generated.

\subsubsection{Neural network software}

Visual Gene Developer 1.7 Software provided by McDonalds et al. (2011) was used to calculate the predicted output. It is open-source software capable of the following features: construction of neural network structure and provision of neural network map analysis and prediction maps. It is of greater advantage over other software available online.

\subsection{Methods}

The study was conducted by following the procedures in Figure 1 . Details of each step are also described in the figure.

\subsubsection{Primary data gathering}

Online and personal interview was conducted as an initial step of data gathering. A survey questionnaire consist of questions such as name, age, location, occupation, no. and brand of cellphones owned, age of having the first cellphone/s, years of using the cellphone/s, reasons for getting new cellphone/s unit and knowledge on waste cellphone disposal were the significant questions asked to the respondents.

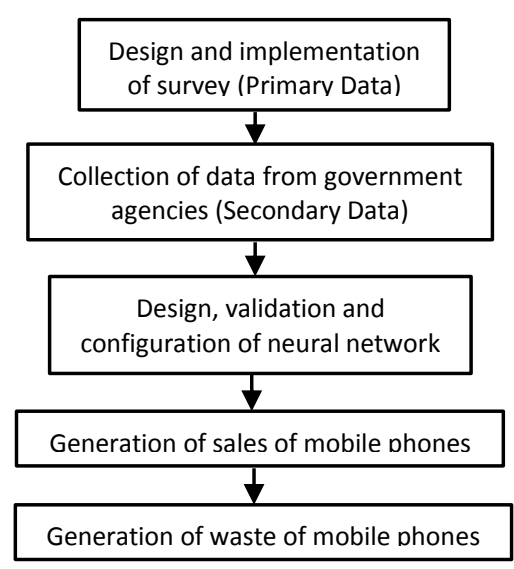

Figure 1. The procedure as conducted in the study

\subsubsection{Secondary data gathering}

Data from different agencies and government offices were obtained and applied as secondary data. Historical data of the input factors were also collected (see Table 3). These historical data will serve as training data set for the neural network. Table 1 shows the input factors used in the study and their corresponding sources.

\subsubsection{Neural network design and validation}

The architecture of ANN is a feed-forward neural network (FFNN) with a topology of 7-6-5-4-3-2-1 using sigmoid activation function to every output neuron (Figure 4).

The degree of validity was determined to measure the accuracy of the neural network model. The validation was done by comparing the results of the neural network model and the present actual data of sales in the Philippines. When the sales volume of mobile phones had been estimated, the quantity of waste mobile phones was estimated next. 
Table 1. Input factors and sources of data

\begin{tabular}{|c|c|c|}
\hline & Input Factor & Source \\
\hline 1 & Population & $\begin{array}{l}\text { Philippine Statistics Authority } \\
\text { (PSA) }\end{array}$ \\
\hline \multirow[b]{2}{*}{2} & \multirow[b]{2}{*}{ Literacy Rate } & $\begin{array}{l}\text { Philippine Statistics Authority } \\
\text { (PSA) }\end{array}$ \\
\hline & & $\begin{array}{l}\text { United Nations Education, } \\
\text { Scientific, and Cultural } \\
\text { Organization (UNESCO) }\end{array}$ \\
\hline 3 & Mobile Connections & $\begin{array}{c}\text { National Telecommunications } \\
\text { Commission (NTC) }\end{array}$ \\
\hline 4 & $\begin{array}{l}\text { Unique Mobile } \\
\text { Subscribers }\end{array}$ & $\begin{array}{c}\text { National Telecommunications } \\
\text { Commission (NTC) }\end{array}$ \\
\hline \multirow{3}{*}{5} & \multirow{3}{*}{$\begin{array}{l}\text { Gross Domestic } \\
\text { Product (GDP) }\end{array}$} & Trading Economics (2016) \\
\hline & & $\begin{array}{l}\text { Philippine Statistics Authority } \\
\text { (PSA) }\end{array}$ \\
\hline & & $\begin{array}{c}\text { Bangko Sentral ng Pilipinas } \\
\text { (BSP) }\end{array}$ \\
\hline \multirow{3}{*}{6} & \multirow{3}{*}{$\begin{array}{l}\text { Average Income } \\
\text { (GDP per Capita) }\end{array}$} & Trading Economics (2016) \\
\hline & & $\begin{array}{l}\text { Philippine Statistics Authority } \\
\text { (PSA) }\end{array}$ \\
\hline & & $\begin{array}{c}\text { Bangko Sentral ng Pilipinas } \\
\text { (BSP) }\end{array}$ \\
\hline \multirow{3}{*}{7} & \multirow{3}{*}{$\begin{array}{l}\text { US Dollar to } \\
\text { Philippine Peso } \\
\text { Exchange Rate }\end{array}$} & Trading Economics (2016) \\
\hline & & $\begin{array}{l}\text { Philippine Stock Exchange, } \\
\text { Inc. (BSP) }\end{array}$ \\
\hline & & $\begin{array}{c}\text { Bangko Sentral ng Pilipinas } \\
\text { (BSP) }\end{array}$ \\
\hline
\end{tabular}

\subsubsection{Neural network configuration}

Neural network training process was conducted using Visual Gene Developer 1.7 Software. During the training process, the software initially normalizes the input data in order to lessen the distance between the magnitudes of the predictors. The next step involves the initialization of the weight of the synapse and compute for the value of neurons to every hidden layer. When the value of neurons to every hidden layer is obtained, an activation function is used to transform the activation level of a unit (neuron) into an output signal. During back-propagation, the system is continuously updating the weight values until the desired error in the output is achieved. The settings in the Visual Gene Developer 1.7 Software employed in this study to obtain the target output are shown in Table 2.

Table 2. Training settings in Visual Gene Developer 1.7 during data training process

\begin{tabular}{cc}
\hline Learning Rate & 0,5 \\
\hline Momentum Coefficient & 0,1 \\
\hline Transfer Function & Sigmoid \\
\hline Maximum No. of Training Cycle & 1.000 .000 .000 \\
\hline Target Error & 0,00001 \\
\hline Analysis Update Interval (Cycles) & 500 \\
\hline
\end{tabular}

\subsubsection{Estimation of waste mobile phones}

Data on waste mobile phones with usage of less than 1 year, between 1 year to 2 years, and 2 years and above were derived from the results of the survey. The model and equation used in estimating waste mobile phones are shown below (see Figure 2 and Equation 1):
Waste Mobile Phone at specific year $(j)=(x$ at $j)+$ (y at $\left.j_{1}\right)+\left(z\right.$ at $\left.j_{2}\right)$

where:

$x=$ waste mobile phone with usage of less than 1 year

$y=$ waste mobile phone with usage of between 1 year to 2 years

$z$ = waste mobile phone with usage of 2 years and above

$\mathrm{j}$ = specific year

$\mathrm{j}_{1}=1$ year before the specific year

$\mathrm{j}_{2}=2$ years before the specific year

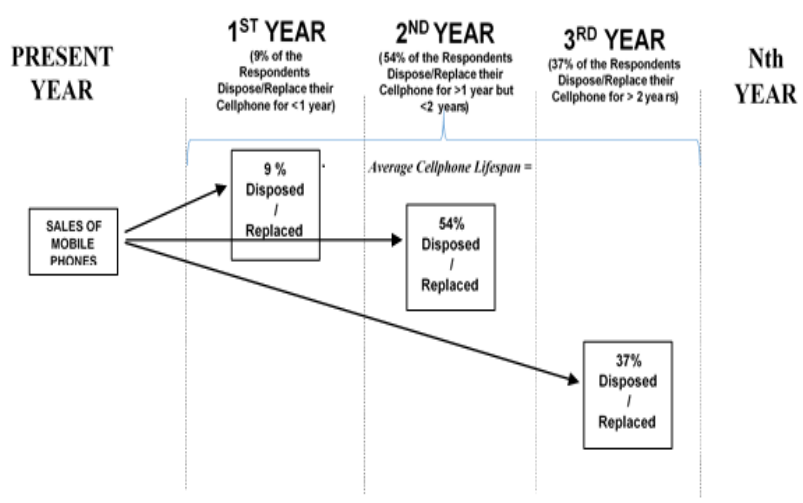

Figure 2. Model for computing waste mobile phones

\section{Results and discussion}

\subsection{Results of the survey}

Figure 3 presents the regional distribution of survey respondents around the country. Out of the total 150 respondents, the most number of respondents were from Region III, Region IV-A and NCR which is $22,67 \%, 14 \%$ and $22,67 \%$ respectively.

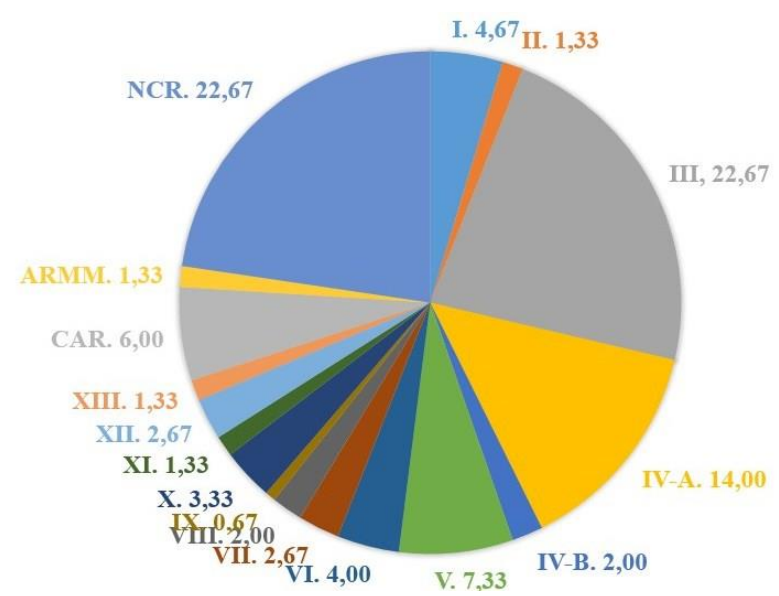

Figure 3. Regional distribution of survey respondents (\%)

Results of the survey indicated that the average number of mobile phones owned per individual is 1,233. The average number of sim cards used per mobile phone is 2,00. Majority of the respondents (91\%) own smartphones while some respondents (9\%) own both smartphones and feature phones. Nine percent of the total respondents disposed and/or replaced their mobile 
phones after less than one year of usage; $54 \%$ disposed and/or replaced their mobile phones after one year to two years of usage; and $37 \%$ disposed and/or replaced their mobile phones when their usage reached 2 years and above. The $9 \%$ of the respondents who disposed and/or replaced their mobile phones after less than one year of usage were mostly users of feature phones.
The analysis showed that the disposal and/or replacement cycle for feature phones is fast because this particular category of mobile phones is cheap. Advanced features and better specifications were among the factors that influence customers' buying preferences. It is worth noting that $95 \%$ of the total respondents have no knowledge on proper disposal of mobile phones.

Table 3. Historical data from different agencies and government offices

\begin{tabular}{|c|c|c|c|c|c|c|c|c|}
\hline \multirow[b]{2}{*}{ Year } & \multicolumn{2}{|c|}{ Demography } & \multicolumn{2}{|c|}{ Mobile operators data } & \multicolumn{4}{|c|}{ Economic credibility } \\
\hline & Population & $\begin{array}{c}\text { Literacy } \\
\text { rate (for } \\
\text { Male \& } \\
\text { Female, \%) }\end{array}$ & $\begin{array}{c}\text { Mobile } \\
\text { connections }\end{array}$ & $\begin{array}{c}\text { Unique } \\
\text { mobile } \\
\text { subscribers }\end{array}$ & GDP (in pesos) & $\begin{array}{c}\text { Ave. } \\
\text { Income } \\
\text { (GDP per } \\
\text { capita, in } \\
\text { pesos) }\end{array}$ & $\begin{array}{c}\text { Dollar to } \\
\text { peso } \\
\text { exchange } \\
\text { rate }\end{array}$ & $\begin{array}{c}\text { Sales of } \\
\text { mobile } \\
\text { phones }\end{array}$ \\
\hline 2010 & 94.013 .200 & 95,6571 & 83.150 .238 & 41.575 .119 & 9.003 .960 .000 .000 & 95.773 & 45,11 & 13.867 .200 \\
\hline 2011 & 95.803 .620 & 95,7857 & 94.189 .275 & 47.094 .638 & 9.705 .770 .000 .000 & 101.309 & 43,31 & 14.501 .600 \\
\hline 2012 & 97.594 .040 & 95,9143 & 101.978 .345 & 50.989 .173 & 10.565 .950 .000 .000 & 108.264 & 42,23 & 17.550 .100 \\
\hline 2013 & 99.384 .460 & 96,0429 & 102.823 .569 & 51.411 .785 & 11.496 .230 .000 .000 & 115.674 & 42,25 & 19.085 .600 \\
\hline 2014 & 101.174 .860 & 96,1714 & 116.835 .776 & 58.417 .888 & 12.633 .390 .000 .000 & 124.867 & 44,39 & 21.296 .300 \\
\hline 2015 & 102.965 .300 & 96,5000 & 130.848 .296 & 65.424 .148 & 13.518.050.000.000 & 131.287 & 45,50 & 23.618 .300 \\
\hline
\end{tabular}

Table 4. Predictor values for the ANN

\begin{tabular}{|c|c|c|c|c|c|c|c|c|}
\hline Year & Population & $\begin{array}{l}\text { Literacy } \\
\text { rate mf } \\
(\%)\end{array}$ & Connections & $\begin{array}{c}\text { Unique } \\
\text { mobile } \\
\text { users }\end{array}$ & GDP (billion peso) & $\begin{array}{c}\text { Ave. } \\
\text { Income } \\
\text { (gdp per } \\
\text { capita) }\end{array}$ & $\begin{array}{c}\text { Dollar to } \\
\text { peso } \\
\text { exchange } \\
\text { rate }\end{array}$ & $\begin{array}{l}\text { Sales Of } \\
\text { cellphone }\end{array}$ \\
\hline 2016 & 104.755 .740 & 96,43 & 144.860 .816 & 72.430 .408 & 14.402 .710 .000 .000 & $137.488,50$ & 45,22 & \multirow{6}{*}{$\begin{array}{c}\text { To be } \\
\text { predicted } \\
\text { by ANN }\end{array}$} \\
\hline 2017 & 106.546 .180 & 96,56 & 158.873 .336 & 79.436 .668 & 15.287 .370 .000 .000 & $143.481,16$ & 43,03 & \\
\hline 2018 & 108.336 .620 & 96,69 & 172.885 .856 & $86,442,928$ & 16.172 .030 .000 .000 & $149.275,75$ & 42,29 & \\
\hline 2019 & 110.127 .060 & 96,81 & 186.898 .376 & 93.449 .188 & 17.056 .690 .000 .000 & $154.881,92$ & 42,69 & \\
\hline 2020 & 111.917 .500 & 96,94 & 200.910 .896 & 100.455 .448 & 17.941 .350 .000 .000 & $160.308,71$ & 43,91 & \\
\hline 2021 & 113.707 .940 & 97,07 & 214.923 .416 & 107.461 .708 & 18.826 .010 .000 .000 & $165.564,60$ & 45,64 & \\
\hline
\end{tabular}

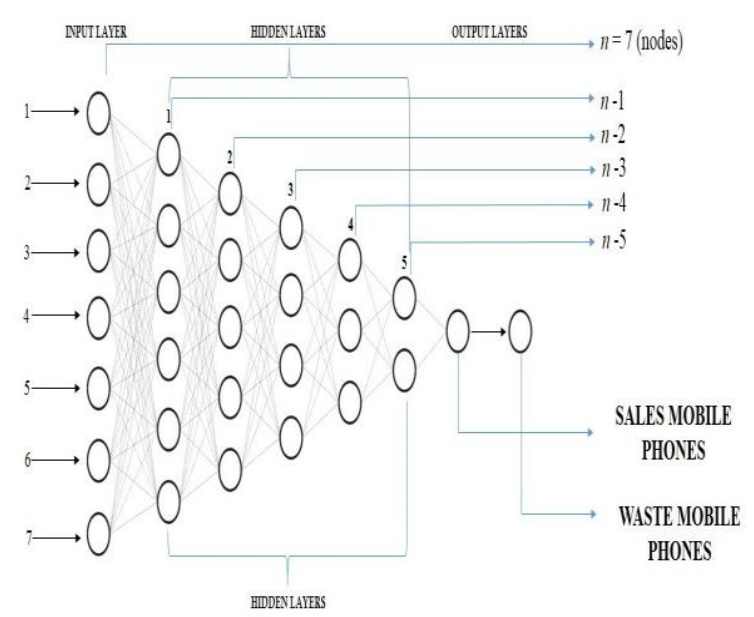

Figure 4. Structure of the neural network model

\subsection{Estimated sales data and model validation}

Figure 5 presents the plot of data between the actual sales of mobile phone volume obtained from the Euromonitor International Journal from 2010 to 2015 versus the experimental sales of mobile phone volume computed using the neural network in terms of number of mobile units. At this point, the efficiency of the model has been validated. The results shows that the data obtained using neural network have a margin of error of $\pm 0.20 \%$ compared to the actual values, $\mathrm{R}^{2}$ is 0,99 . Due to the small margin of errors, the actual sales of mobile phone overlaps the experimental values in the graph. In this case, neural networks demonstrated feasible solution to solve a non-linear problem that is advantageous than statistical methods (Figure 5).

Figure 6 indicates that at an increasing number of iterations, the SSE is decreasing. The best training in the neural network can be achieved when the SSE is no longer converging. The graph shows that during $1,54 \times 10^{6}$ iterations, the SSE is $9,9 \times 10^{-6}$. The SSE value was negligibly changing albeit the number of iterations was increased. At this point, we can say that the output values at this interval are the ideal results of the prediction.

During the training process, the model has established synaptic connections between the input, hidden 
and output neurons. These connection contains different weight values needed in the prediction. Visual Gene Developer 1.7 Software is limited to providing the actual value of weight however, a neural network map analysis is provided as shown in Figure 7.

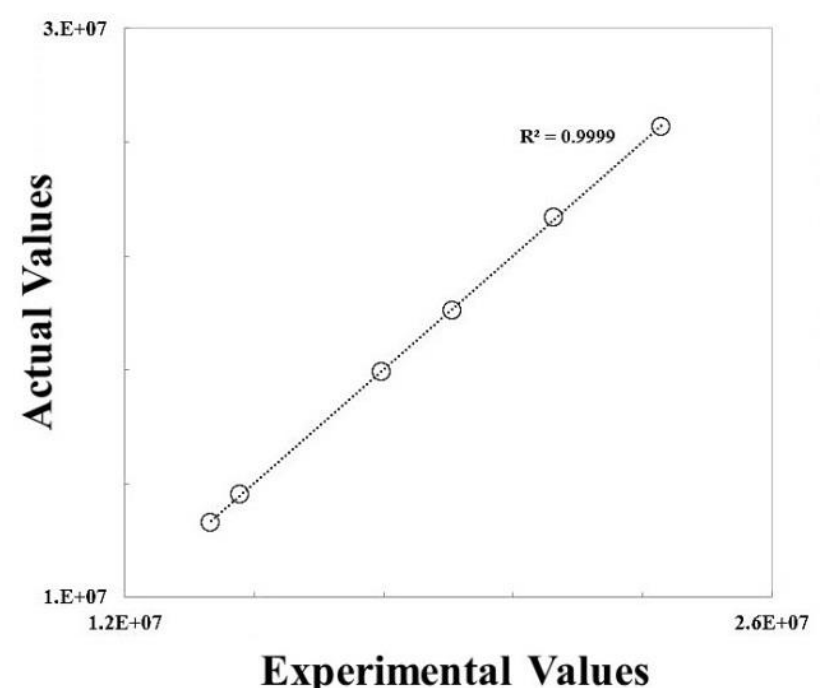

Figure 5. Actual vs. experimental values of sales of mobile phones in terms of number of mobile units

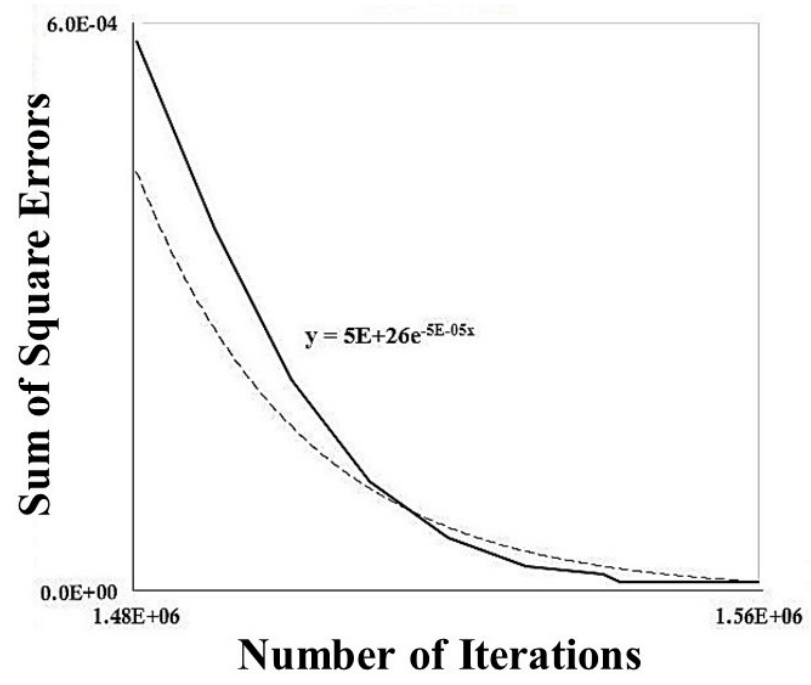

Figure 6. Relationship between number of iterations and sum of squared errors

Figure 7 shows the weight of the synapse connected to every neuron with the aid of Visual Gene Developer 1.7 Software. This diagram provide insight into variable importance by visually examining the weights between the neuron layers. The legend indicates that near the "red" color, the value of the weight is approaching a positive value whereas near the "violet" color, the weight is approaching a negative value.

In predicting the values from 2016-2021, predictor data sets are necessary to conduct simulation. The predictor values (Table 4) used in the model were also collected from the same agencies in Table 1 . These government agencies used statistical methods such as linear extrapolation to calculate their own forecasted data. This study used the given predictor data for the sake of generating waste estimates since at this moment, the real predictor data from 2016-2021 are not available.

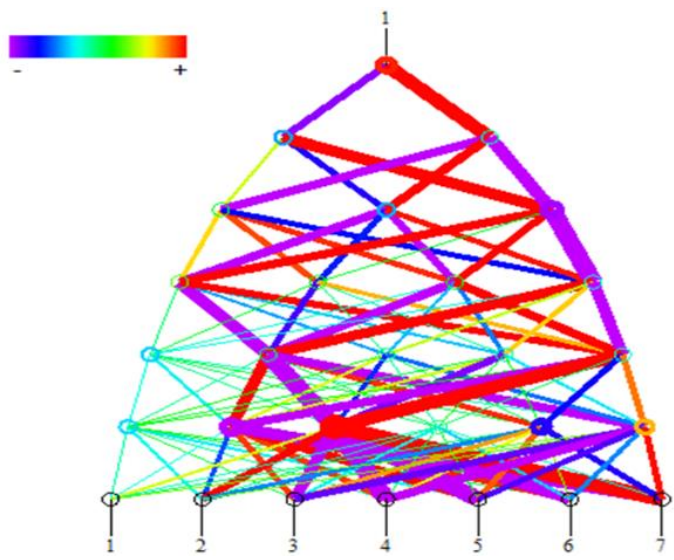

Figure 7. Neural network map analysis

The results from the neural networks are presented in Table 5.

Table 5. Sales of mobile phones

\begin{tabular}{cc}
\hline Year & Estimated sales of mobile phones \\
\hline 2016 & 24.638 .606 \\
\hline 2017 & 24.846 .842 \\
\hline 2018 & 24.888 .616 \\
\hline 2019 & 24.903 .568 \\
\hline 2020 & 24.910 .788 \\
\hline 2021 & 24.914 .970 \\
\hline
\end{tabular}

Using Equation 1, the volume of estimated waste mobile phones from 2010 to 2021 is presented in Table 6.

Due to the absence of data from the government agencies during the past years, this study used the data since 2010 as the starting point. During this year also where the estimation of waste mobile phone was taken into consideration.

Table 6. Waste mobile phones

\begin{tabular}{cc}
\hline Year & Estimated waste mobile phones \\
\hline 2010 & 1.248 .048 \\
\hline 2011 & 8.793 .432 \\
\hline 2012 & 14.541 .237 \\
\hline 2013 & 16.560 .350 \\
\hline 2014 & 18.716 .428 \\
\hline 2015 & 20.687 .321 \\
\hline 2016 & 22.850 .988 \\
\hline 2017 & 24.279 .834 \\
\hline 2018 & 24.773 .554 \\
\hline 2019 & 24.874 .505 \\
\hline 2020 & 24.898 .686 \\
\hline 2021 & 24.908 .493 \\
\hline
\end{tabular}

In 2010-2015, the results of waste mobile phones were unstable and the model was in the stage of building up baseline data, however, in the year 2016-2021, stability was achieved, although a small increase in estimates was observed per year. The volume of waste estimates in 
2016-2021 was highly affected by the sales output from the neural network.

By examining the predictor values in neural networks, the effect of linear extrapolation used by the government agencies affects the results of neural network by producing a pattern with minimal data increase per year.

When these predictor set fed to the neural networks, the model acquired the pattern and generated output values that consist of small increase per year as well.In modelling using neural network, realistic and more numbers of observations is desirable in the training set to achieve good generalization.

\section{Conclusions and recommendations}

Demand for mobile phones will continuously increase. Based on the response to the survey questionnaire and the findings in GSMA Intelligence (2015), the main factors that influence the decision making of consumers in buying mobile phones are the price and the advanced features of the unit This study no longer considered these factors as input due to the following reasons: (1) data in mobile phone possession are already given, (2) input parameters were all quantitative variables while advance features of mobile phone will fall under categorical variable. Mobile phone as compared to other electronic products is relatively small in terms of gross weight but its waste generation has a significant impact on the environment due to its fast replacement rate. Since this type of e-waste is increasing in volume, it poses a threat not only to the environment but also to human health when not properly managed. Realizing this threat, this study attempted to do the primary step to address it by estimating the volume of waste mobile phones in the country. The study was able to estimate data on sales of mobile phones and subsequently, the waste mobile phones in the country from 2010 to 2021. With 5 hidden layers, the Visual Gene Developer 1.7 Software achieved sum of squared error of \pm 0.00001 . Estimates and predicted values were found to be in good agreement with a calculated accuracy of $99 \%$. Neural network is a black box model meaning, in the real world, the only visible are the input and output parameters. Neural networks are proven to be accurate as compared to statistical methods, however, it cannot display how the input variables behave and influence individually the target output. Moreover, other techniques may be applied such as sensitivity analysis to evaluate the impact of input factors with respect to the target output. Estimates from this study may be used by policy makers as basis for strategy formulation and as guideline and baseline data for establishing a proper management system. The neural network also performed better than the traditional linear extrapolation method for forecasting of data. This accuracy of the neural network method is encouraging but it rely on the accuracy of the input data as well. It is therefore recommended that the input factors be further explored for more realistic estimates. The training settings in Visual Gene Developer 1.7 Software can also be improved to obtain a faster learning process.

\section{References}

Araújo M., Magrini A., Mahler C. and Bilitewski B. (2012), A model for estimation of potential generation of waste electrical and electronic equipment in Brazil, Waste Management, 32, 335-342.

Carisma B. (2009), Drivers of and Barriers to E-waste Management in the Philippines. IIIEE Theses 2009:03.

Dwivedy M. and Mittal R.K. (2010), Estimation of future outflows of e-waste in India, Waste Management, 30, 483-491.

Environmental Management Bureau (1990), Toxic Substances and Hazardous and Nuclear Wastes Control Act of 1990, RA6969, Retrieved from http://www.emb.gov.ph

Euromonitor International Journal (2015), Mobile Phones in the Philippines.

GSMA Intelligence (2014), Country overview: philippines growth through innovation.

GSMA Intelligence (2015), The mobile economy asia pacific 2015.

Habuer, Nakatani J. and Moriguchi Y. (2014), Time-series product and substance flow analyses of end-of-life electrical and electronic equipment in China, Waste Management, 34(2), 489-497.

Jones E. (2004), An Introduction to Neural Networks, Visual Numerics, Inc., Dec. 2004

Karen M. and Sang-Kyu J. (2011), Visual gene developer: a fully programmable bioinformatics software for synthetic gene optimization, BMC Bioinformatics, 12(1), 340.

Li B., Yang J., Lu B. and Song X. (2014), Estimation of retired mobile phones generation in china: a comparative study on methodology, Waste Management, 35(2015), 247-254.

Oancea B. and Ciucu S. (2005), Time series forecasting using neural networks, Nicolae Titulescu University of Bucharest.

Peralta G. and Fontanos P. (2006), E-waste issues and measures in the Philippines, Journal of Material Cycles and Waste Management, 8(1), 34-39.

Petridis N., Stiakakis E. and Petridis K. and Dey P. (2015), Estimation of computer waste quantities using forecasting techniques, Journal of Cleaner Production, 112, 3072-3085.

Polák M. and Drápalová L. (2012), Estimation of end of life mobile phones generation: The case study of the Czech Republic, Waste Management, 32(8), 1583-1591.

Sata M. (2013), Factors affecting consumer buying behavior of mobile phone devices, Mediterranean Journal of Social Sciences, 4(12), 103-112.

Sohl J.E. and Venkatachalam A.R. (1995), A neural network approach to forecasting model selection, Information and Management, 29(6), 297-303.

Steubing B., Boni H. Schluep M., Silva U. and Ludwig C. (2010), Assessing computer waste generation in chile using material flow analysis, Waste Management, 30(2010), 473-482.

The Statistics Portal, Number of mobile phone users in the Philippines from 2014 to 2020 (in millions), Retrieved from www.statista.com

Theodoridis S. (2015), Chapter 18- neural networks and deep learning, Machine Learning: A Bayesian and Optimization Perspective, 2015, 875-936.

Wang F., Huisman J., Stevels A. and Baldé C. (2013), Enhancing ewaste estimates: Improving data quality by multivariate Input-output analysis, Waste Management, 33(11), 23972407. 